\title{
Novos elementos sobre praxes no ensino superior - estudos na Universidade dos
}

Açores

\section{New elements on hazing in higher education - studies at the University of the}

\author{
Azores \\ Maria Mendes*, Suzana Nunes Caldeira**, Osvaldo Silva**, Áurea Sousa***, Maria José D. Martins**** \\ *Universidade dos Açores, GaPEOS, ** Universidade dos Açores, Centro Interdisciplinar de Ciências Sociais - \\ CICS.UAc/CICS.NOVA.UAc, ***Universidade dos Açores, CEEAplA, **** Instituto Politécnico de Portalegre, UIDEF-IEUL, \\ CIEP - UE
}

\begin{abstract}
Resumo
Este trabalho procura elementos que contribuam para um melhor entendimento da expressão tendencialmente positiva face à praxe académica, por parte de estudantes caloiros de uma instituição de ensino superior em Portugal. Participaram no estudo 163 estudantes de $1 .^{\circ}$ ano e de ambos os sexos que responderam ao Questionário de Vivências da Praxe (QVP), de Vieira (2012), e ao Questionário de Integração Social no Ensino Superior (QISES), de Diniz, 2017. Os principais resultados indicam existir mais alunos a afirmarem sentir-se integrados, em detrimento de ansiosos (QVP), e que o sentimento de integração relaciona com a Relação com os Amigos (QISES).
\end{abstract}

Palavras chave: Ensino superior, praxe académica, integração social.

\begin{abstract}
This work looks for elements that contribute to a better understanding of the tendentially positive expression towards the academic hazing, by freshmen students of a higher education institution in Portugal. The study was attended by 163 first year's students of both sexes who answered the Hazing Living Experiences Questionnaire (QVP), of Vieira (2012), and Social Integration in Higher Education Questionnaire (QISES), by Diniz (2017). The main results indicate that there are more students claiming to be integrated, rather than anxious (QVP), and that the feeling of integration relates to the Relationship with Friends (QISES).

Keywords: Higher education, practice hazing, social integration.
\end{abstract}

\section{Introdução}

Acontecimentos trágicos no país ocorridos com estudantes do Ensino Superior, alguns dos quais culminando em mortes de jovens, têm sido alegadamente atribuídos a rituais praxistas. Esta circunstância tem contribuído para uma maior atenção e disseminação de informações e alertas sobre este tema, por parte da entidade que tutela o Ensino Superior em Portugal (Resolução da Assembleia da República n. ${ }^{\circ}$ 38/2016) e pelas próprias instituições de ensino superior. Também muito tem sido escrito e falado na comunicação social sobre este assunto (e.g., Silva, 2017). Tudo isto tem dado uma maior centralidade a um fenómeno que antes ficava mais cometido aos estudantes praxantes e praxados.

$\mathrm{Na}$ Universidade dos Açores, instituição em foco neste trabalho, os primeiros estudos sobre este tópico procuraram conhecer a tónica, positiva ou negativa, com que os estudantes caracterizavam a sua relação com a praxe. Os resultados, alcançados através de uma escala construída por Matos, Jesus, Simões e Nave (2010) com o objetivo de medir a relação dos estudantes com as praxes, apontaram para a ideia de que os estudantes tendiam a manter uma relação mais positiva do que negativa com os rituais de praxe, embora estes fossem vividos apenas por uma parcela dos caloiros (Caldeira, Silva, Mendes, \& Botelho, 2015a; Caldeira, Silva, Mendes \& Botelho, 2015b; Caldeira, Silva, Mendes, Botelho \& Martins, 2016; Caldeira, Sousa, Silva, Mendes \& Martins, 2016).

Estes primeiros resultados foram dissonantes de outros mais dominantemente disseminados em estudos científicos que indicavam as atividades de praxe como situações caracterizadas pelo abuso de poder entre pares, marcando a desigualdade de uma relação que, por princípio, deveria ser horizontal. Em termos de comportamentos concretos, a investigação aponta sistematicamente para o mesmo tipo de situação. No cenário internacional dá-se como exemplo a referência a ações de ridicularização de colegas mais velhos sobre os novatos, o incentivo ao consumo excessivo de bebidas alcoólicas, ou a existência de episódios de humilhação a que os mais novos são sujeitos (Knutson, Akers, Ellis \& Bradley, 2011). Em relação ao nosso país, os resultados a que chegaram Dias e Sá (2013) são, também, ilustrativos deste lado prepotente e negro da praxe. Estas autoras concluíram que uma proporção ainda elevada dos estudantes participantes na investigação afirmava a praxe e, principalmente, o medo que esta gerava, como um dos aspetos mais impactantes, pela negativa, da entrada no Ensino Superior. 
Estes dois casos sublinhando os aspetos negativos da praxe, repescados de outros análogos que se encontram na literatura na área (e.g., Allan \& Madden, 2008; Costa, Dias, Dias, Souza \& Canela, 2013), contrastam a posição mais comum dos jovens inicialmente inquiridos na Universidade dos Açores. Estes, como mencionado, afirmaram manter uma relação tendencialmente positiva, animada e cordial com os acontecimentos e as vivências da praxe. Para grande parte deles, a praxe configura-se como uma atividade atrativa e exerce um efeito integrador. Assim sendo, presume-se que deverá colher um elevado número de adeptos e que os recém-entrados facilmente encetam e estabelecem novas e profícuas dinâmicas relacionais.

Foi esta intenção de clarificação do modo como os estudantes da Universidade dos Açores dizem percecionar a praxe que norteou este trabalho. Deu-se atenção a eventuais diferenças entre sexos e a casos cuja frequência do Ensino Superior implicou mudança de residência. Procurou-se, finalmente, conjeturar se a relação positiva, afirmada pelos primeiros respondentes, teve um efeito propagador e ocasionou um maior número de adesões a este ritual de entrada, proporcionalmente a anos anteriores.

\section{Método}

\section{Participantes}

A amostra foi constituída por 163 estudantes do $1^{\circ}$ ano de diversas áreas de estudo da Universidade dos Açores, $44.2 \%$ do sexo masculino e $55.8 \%$ do feminino, com idades entre os 18 e os 47 anos.

\section{Instrumento}

A recolha de dados foi efetuada através de um protocolo que continha uma parte relativa a dados pessoais, académicos e familiares, uma adaptação do Questionário de Vivências da Praxe (QVP), estudado para a população portuguesa por Vieira em 2013, e o Questionário de Integração Social no Ensino Superior (QISES), estudado para a população portuguesa por Diniz em 2017.

Adotou-se o QVP e não a escala de Matos et al. (2010), pois havia a expectativa de que através deste questionário, que acede às perceções dos estudantes sobre as vivências da praxe, se perceberia melhor as razões subjacentes à relação positiva que aqueles diziam manter com estes rituais de entrada. A adaptação do QVP, aqui considerada, integra duas subescalas referentes, respetivamente, à Integração e à Ansiedade percebidas no contexto da praxe. A primeira é constituída por dez itens $(1,3,4,5,7,9,11,13,15$ e 17$)$ e a segunda por oito itens $(2,6,8,10,12,14,16,18)$, e os enunciados dos mesmos são apresentados na Tabela1.
Tabela 1

Itens do QVP

1. A adesão à Praxe facilitou a minha integração no curso.

2. Quando ingressei no Ensino Superior, o facto de tomar conhecimento da existência da Praxe, fez aumentar a minha ansiedade.

3. O conhecimento prévio acerca do que é a Praxe influenciou a minha decisão de aderir à mesma.

4. Sinto que as experiências que a Praxe me proporcionaram foram, em muito, positivas.

5. Para mim, a Praxe é sinónimo de acolhimento e integração.

6. A minha experiência com a vivência da Praxe leva-me a achar que as suas atividades são violentas.

7. Os meus amigos mais chegados participaram na Praxe.

8. Em algumas situações senti-me humilhado/a enquanto estava a ser praxado/a.

9. A minha Praxe foi mais integradora devido ao seu bom uso pela minha faculdade/universidade.

10. Sinto que houve situações em que, alunos que não participaram na Praxe, mostravam sentir-se discriminados.

11. Eu participei na Praxe de livre vontade.

12. Em alguns momentos senti-me constrangido/a em fazer o que os "doutores" mandavam.

13. Sinto que o meu envolvimento na Praxe me motivou a ir às aulas e a dedicar-me ao meu curso.

14. Houve situações em que senti que os meus "doutores" não fizeram um uso mais positivo do seu poder na Praxe.

15. Acho que os meus "doutores" praxam porque, no seu ano de caloiros, gostaram das experiências que as Praxes lhe proporcionaram.

16. Ponderei, algumas vezes, se sairia à noite por ter receio de ser apanhado/a por "doutores".

17. Para mim, ter sido praxado, fez com que me relacionasse mais facilmente com os meus novos colegas.

18. Em algumas situações, senti vontade de fugir à Praxe.

O QISES é constituído por 20 itens distribuídos equitativamente por 5 fatores: Equilíbrio Emocional (EE), Relações com Colegas (RC), Relações com Professores (RP), Relações com Família (RF) e Relações com Amigos (RA)

Os itens que compõem ambos os questionários são mensurados numa escala de Likert de acordo (1-Discordo Totalmente (DT); 2- Discordo (D); 3 - Não Discordo Nem Concordo (NDNC); 4- Concordo (C); 5- Concordo Totalmente (CT)).

\section{Procedimento}

Os dados foram recolhidos em ambiente de sala de aula, os estudantes foram informados sobre o objetivo geral do estudo, a participação deles foi voluntária e os dados foram tratados de modo a garantir a confidencialidade dos respondentes. Foram calculadas as pontuações totais dos estudantes nas subescalas do QVP e do QISES e na escala total do QISES. A não verificação do pressuposto de normalidade das pontuações obtidas, segundo o teste de Kolmogorov-Smirnov (K-S) com a correção de Lilliefors, está na base do recurso a uma abordagem não paramétrica, tendo-se utilizado o teste de Mann-Whitney, com vista à comparação entre géneros e entre estudantes cuja a entrada na universidade implicou a mudança de 
residência e os restantes, no que se refere a essas pontuações. Para estudar a relação entre os resultados do QVP e do QISES recorreu-se ao coeficiente de correlação de Spearman.

\section{Resultados}

A análise da distribuição das respostas dos inquiridos ao QVP revelou que a proporção mais elevada de respostas de acordo se situa na subescala Integração, com saliência para os itens 11,5 e 4, onde, respetivamente, $45 \%, 22.4 \%$ e $22.3 \%$ dos participantes assinalaram a categoria CT. A subescala Ansiedade colheu poucas manifestações de acordo. A mais elevada, com $8.2 \%$ na categoria CT, recaiu sobre o item 18 . Acresce que nesta subescala o item 16 apresentou moda igual a "Discordo Totalmente", o item 6 apresentou duas modas, nas categorias DT e NDNC e todos os outros itens tiveram moda igual a "Não Discordo Nem Concordo".

Ainda, no caso da subescala Integração, os valores da média (32.36) e da mediana (31.5) das pontuações totais são ligeiramente superiores ao ponto médio (30) do intervalo de variação desta subescala $[10,50]$. Já no caso da subescala Ansiedade, os valores da média (19.77) e da mediana (22.0) das pontuações totais são ligeiramente inferiores ao ponto médio (24) do intervalo de variação desta subescala $[8,40]$. Com base no coeficiente de variação, é possível concluir que a variabilidade das pontuações obtidas foi mais elevada no caso da subescala Ansiedade (32.21\%) comparativamente à Integração $(30.85 \%)$. Numa análise por sexos, os resultados, utilizando o teste de Mann-Whitney, apontam para a inexistência de diferenças estatisticamente significativas entre os rapazes e as raparigas a nível das pontuações obtidas nas duas subescalas do QVP (Integração: $\mathrm{U}=1412.5$; $\mathrm{p}=0.232$; Ansiedade: $\mathrm{U}=1627.0$; $\mathrm{p}=0.461$ ). Numa análise tomando em atenção os estudantes cuja entrada na universidade implicou mudança de residência e os restantes, os resultados indicam diferenças estatisticamente significativas $(U=804 ; p=0.025)$, no que se refere apenas às pontuações obtidas na subescala integração do QVP, com os primeiros a obterem pontuações mais elevadas $(\mathrm{MR}=69.58$ versus $\mathrm{MR}=53.24$ ).

Quanto ao QISES, os valores das médias das pontuações na escala e nas suas diferentes subescalas, no total da amostra e segundo o sexo, são apresentados na Tabela 2 .

Tabela 2.

Valores da média das pontuações obtidas na escala e nas subescalas EE, RC, RP, RF e RA do QISES, no total da amostra e segundo o sexo.

\begin{tabular}{lccc}
\hline & Total & Masculino & Feminino \\
\hline QISES & 71.37 & 69.33 & $\mathbf{7 3 . 0 1}$ \\
RC & 14.72 & 14.49 & $\mathbf{1 4 . 9 1}$ \\
\hline RP & 14.31 & 13.85 & $\mathbf{1 4 . 6 7}$ \\
RF & 15.59 & 14.36 & $\mathbf{1 6 . 5 6}$ \\
RA & 14.74 & 13.85 & $\mathbf{1 5 . 4 4}$ \\
\hline
\end{tabular}

Observa-se, a partir da Tabela 2, que os valores das pontuações médias são ligeiramente superiores no sexo feminino em todas as subescalas, exceto na EE, com diferenças significativas no caso da escala $(\mathrm{U}=2232$, $\mathrm{p}=0.038)$ e das subescalas $\mathrm{RP}(\mathrm{U}=2503, \mathrm{p}=0.023)$; $\mathrm{RF}$ $(\mathrm{U}=1903.5, \mathrm{p}=0.000)$; e RA $(\mathrm{U}=2117.5, \mathrm{p}=0.000)$.

Existem, também, diferenças significativas ( $U=1620$, $\mathrm{p}=0.010$ ) entre os estudantes cuja entrada na universidade implicou uma mudança de residência e os restantes, mas apenas ao nível das pontuações obtidas na subescala RA, com os primeiros a obterem pontuações, em geral, mais elevadas $(\mathrm{MR}=98.5$ versus $\mathrm{MR}=75.96)$.

Analisando o QVP e o QISES conjuntamente, utilizando o coeficiente de correlação de Spearman, verificou-se a existência de:

- uma correlação positiva baixa, mas estatisticamente significativa, entre as pontuações obtidas nas subescalas Integração do QVP e RA do QISES $\left(\mathrm{r}_{\mathrm{s}}=0.247 ; \mathrm{p}=0.008\right)$;

- uma correlação positiva baixa (inferior a 0.3), mas estatisticamente significativa, entre a maioria dos pares de itens, em que um item é referente à subescala Integração do QVP e o outro à subescala RA do QISES;

- uma correlação negativa baixa, mas estatisticamente significativa, entre as pontuações obtidas na subescala Ansiedade do QVP e as pontuações obtidas nas subescalas $\mathrm{RC}\left(\mathrm{r}_{\mathrm{s}}=-0.275, \mathrm{p}=0.003\right)$ e RP do QISES $\left(r_{s}=-0.363, p=0.000\right)$. Importa salientar que todos os itens da subescala Integração, com exceção de três (itens 3, 9 e 15), apresentam correlações positivas, estatisticamente significativas, com a pontuação total da subescala RA do QISES, embora estas sejam muito baixas (inferiores a 0.3 ).

No entanto, e apesar desta tónica positiva, a proporção de estudantes que vivenciaram a praxe de uma forma mais positiva/favorável/satisfatória $(40.4 \%)$ é inferior à dos que a não a vivenciaram dessa forma.

\section{Discussão}

Os principais resultados do QVP indicam que a Integração tende a prevalecer sobre a Ansiedade, com uma elevada proporção de estudantes a afirmar ter aderido à praxe voluntariamente (item 11), a considerála como meio de acolhimento e integração (item 5) e a encontrar atratividade nas atividades realizadas (item 4). Estas situações ajudam a compreender e a corroborar a ideia, já antes manifestada, de uma relação não negativa com estes rituais de entrada (Caldeira, Silva, Mendes \& Botelho, 2015b). Parece, então, que, na perspetiva dos estudantes da Universidade dos Açores, a exposição e a participação na praxe são, essencialmente, elementos facilitadores da adaptação e da criação de vínculos aos novos pares e à instituição.

Os valores da análise diferencial em função do sexo (teste de Mann-Whitney) apontam para a inexistência de diferenças estatisticamente significativas no que se refere às pontuações obtidas nas duas subescalas do QVP. Por outro lado, indicam a existência diferenças estatisticamente significativas $(\mathrm{U}=866 ; \mathrm{p}=0.033)$ ao nível das pontuações obtidas na subescala Integração entre os 
estudantes cuja entrada na universidade implicou uma mudança de residência e os restantes, com os primeiros a obterem pontuações mais elevadas. Este resultado vem acentuar a ideia de que a praxe, nesta instituição, é geralmente percebida pelos estudantes caloiros como promotora da integração. Os estudantes que mudam de residência enfraquecem a ligação aos seus grupos anteriores de suporte e, por isso, têm um desafio maior para estabelecer novas ligações e novas amizades. $\mathrm{O}$ contexto de praxe parece ser visto como facultador dessa oportunidade.

Claro que também se pode presumir que esses estudantes, precisamente por estarem mais vulneráveis em termos de relações sociais, alimentam a expetativa de que a submissão e a subordinação aos mais velhos lhes trarão ganhos secundários. A ser assim, poder-se-ia falar no fenómeno da profecia autorrealizada, com algum enviesamento atitudinal por parte dos estudantes praxados. Uma referência, ainda, para salientar que todos os itens da subescala Integração, com exceção de três (itens 3, 9 e 15), apresentam correlações estatisticamente significativas com a subescala Relação com Amigos do QISES, situação que vem enfatizar o papel positivo que os estudantes tendem a atribuir à praxe.

No entanto, e apesar desta tónica positiva, a proporção de estudantes que afirma ter aderido à praxe mantém-se reduzida. Este dado não pode deixar de ser considerado e de levantar a possibilidade de que é necessário um estudo com características e contornos distintos dos realizados até ao momento. Para melhor se compreender toda esta realidade, será relevante o recurso a outros métodos de recolha de dados, onde cada um dos sujeitos, confrontado com um conjunto de questões, construa as suas próprias respostas.

\section{Referências}

Allan, E., \& Madden, M. (2008). Hazing in view: College students at risck. Initial findings from the national study of student hazings from the national study of student hazing. http://www.stophazing.org/wpcontent/uploads/2014/06/hazing_in_view_web1.pdf

Caldeira, S. N., Silva, O., Mendes, M., \& Botelho, S. P. (2015a). Hazing practices in higher education: a study with portuguese students. International Journal of Current Research, 7(04), 15444-15447. http://repositorio.uac.pt/bitstream/10400.3/3680/1/haz ing.pdf

Caldeira, S., Silva, O, Mendes, M., \& Botelho, S. (2015b). Praxe académica: meio de integração ou ações de humilhação? Aprender, 36, 102-112, ISSN 0871-1267.

http://repositorio.uac.pt/bitstream/10400.3/3717/1/apr ender $\% 2036 \% 20-\% 20 a 9$.pdf

Caldeira, S. N., Silva, O., Mendes, M., Botelho, S. P., \& Martins, M. J. (2016). University Student's perceptions of hazing: a gender approach. International Journal of Development Research, 6(9), 9444-9449. http://repositorio.uac.pt/bitstream/10400.3/3949/1/201 6-4377_IJDR_publicado.pdf
Caldeira, S. N., Sousa, Á., Silva, O., Mendes, M., \& Martins, M. J. (2016). Relações de género, vivências das praxes, satisfação com a vida e envolvimento do estudante. In Veiga, F. H. (Coord.), Envolvimento dos Alunos na Escola: Perspetivas da Psicologia e Educação para o Desempenho Académico, (pp. 600618), Instituto de Educação, Universidade de Lisboa, Lisboa, Portugal. ISBN 978-989-8753-34-2. http://www.ie.ulisboa.pt/investigacao/publicacoes/livr os-de-atas/atas-do-ii-congresso-internacionalenvolvimento-dos-alunos-na-escola/

Costa, S. M., Dias, O. V., Dias, A C.., Souza, T. R., \& Canela, J. R. (2013). Trote universitário: diversão ou constrangimento entre acadêmicos da saúde? Revista Bioética, 21(2), 350-358. Disponível em http://www.redalyc.org/html/3615/361533262019/

Dias, D., \& Sá, M. J. (2013). Rituais de transição no ensino superior português: A praxe enquanto processo de reconfiguração identitária. Revista GalegoPortuguesa de Psicoloxía e Educación, 21(1) ISSN: 1138-1663.

http://ruc.udc.es/dspace/bitstream/handle/2183/12618/ RGP 212013 art 2.pdf? sequence=1

Diniz, $\bar{A} . \bar{M}$. (2017). Questionário de integração social no ensino superior. In L S. Almeida, M. R. Simões, \& M. M. Gonçalves (Coords.), Adaptação, Desenvolvimento e Sucesso Académico dos Estudantes do Ensino Superior: instrumentos de avaliação (pp. 21-32). Braga: Associação para o Desenvolvimento a Investigação em Psicologia da Educação.

Knutson, N. M., Akers, K. S., Ellis, C. K., \& Bradley, K. D. (2011). Applying the Rasch Model to explore new college sorority and fraternity members' perceptions of hazing behavior. In Mid-Western Educational Research Association annual meeting. http://www.uky.edu/ kdbrad2/MWERA_Nikki.pdf

Matos, F., Jesus, S., Simões, H., \& Nave, F. (2010). Escala para avaliação das situações de bullying nas praxes do ensino superior.Psyc@w@re, 3(1). http://www1.ci.uc.pt/ipc/20072010/revista/c6944bceb08cb00930b00b6645171101.p df

Resolução da Assembleia da República n. ${ }^{\circ}$ 38/2016 (2016, 26, fev.). Recomenda ao Governo o reforço de medidas sobre a praxe académica. Diário da República, 1. ${ }^{\text {a }}$ série, N. ${ }^{\circ} 40$, p.630. Disponível em https://dre.pt/application/conteudo/73727194

Siva, S. (2017, 06, mar.). Praxe, uma história polémica. $O$ https://www.publico.pt/2017/03/06/sociedade/noticia/ praxe-uma-historia-polemica-1763866

Vieira, P. (2013). Vivências da praxe académica: percepção de integração e ansiedade na transição para o ensino superior (Tese de Mestrado, Universidade de Coimbra, Coimbra). https://eg.sib.uc.pt/bitstream/10316/25316/1/Patricia.p df 